\title{
CORRIGENDUM
}

\section{Hydrodynamic-driven morphogenesis of karst draperies: spatio-temporal analysis of the two-dimensional impulse response - CORRIGENDUM}

\author{
P.G. Ledda, G. Balestra, G. Lerisson, B. Scheid, M. Wyart and F. Gallaire
}

doi:10.1017/jfm.2020.1010, Published by Cambridge University Press, 22 January 2021

We found an error in (2.4) of Ledda et al. (2021). The correct non-dimensional expression for the curvature of the free surface is

$$
\kappa=\nabla \cdot\left(\frac{\nabla\left(h+h^{0}\right)}{\sqrt{1+\left(\frac{h_{N}}{l_{c}^{*}}\right)^{2}\left|\nabla\left(h+h^{0}\right)\right|^{2}}}\right) .
$$

While this error does not bear any consequence in the linear analysis at the core of this paper, the value $h_{N} / l_{c}^{*}=1$ has to be specified in figures $15,16,17,21$, without altering the discussion.

Funding. We acknowledge the Swiss National Science Foundation under grant 200021_178971.

Declaration of interests. The authors report no conflict of interest.
Author ORCIDs.
(1) P.G. Ledda https://orcid.org/0000-0003-4435-8613;
(ㄱ) G. Balestra https://orcid.org/0000-0003-0954-5157;
(ㄱ) B. Scheid https://orcid.org/0000-0001-7268-581X;
(1) F. Gallaire https://orcid.org/0000-0002-3029-1457.

\section{REFERENCE}

Ledda, P.G., Balestra, G., Lerisson, G., Scheid, B., Wyart, M. \& Gallaire, F. 2021 Hydrodynamic-driven morphogenesis of karst draperies: spatio-temporal analysis of the two-dimensional impulse response. J. Fluid Mech. 910, A53. 